\title{
BERNABE GIL, DAVID, Tierra y sociedad en el Bajo Segura (1700-1750), Alicante, Colección Universidad, 1982, 235 pp.
}

Por Armando ALBEROLA ROMÁ

El Secretariado de Publicaciones de la Universidad alicantina inicia con este libro de David Bernabé Gil la que deseamos sea una larga y fructifera andadura en la que, periódicamente, se dé a conocer el estado de las investigaciones llevadas a cabo por los integrantes de este casi recién creado campus.

Tierra y sociedad en el Bajo Segura constituye la Memoria de Licenciatura del autor y, a lo largo de 230 páginas, desarrolla un interesante y documentado estudio de historia rural cuya localización, tanto geográfica como cronológica, ya es de por sí sugerente.

La comarca del Bajo Segura, con el importante enclave urbano de Orihuela, se presentaba en la actualidad como una zona casi huérfana de estudios rigurosos $\left({ }^{*}\right)$, de la cual se ignoraba el desarrollo de la problemática agrosocial así como la caracterización de sus estructuras agrarias y la evolución del régimen señorial. El marco cronológico en que se centra el estudio, elegido por el autor por razones metodológicas, presenta los rasgos de una etapa de gran expansión demográfica y económica- «la primera expansión del XVIII", en frase de Bernabé Gil-tras el estancamiento y retroceso vividos en la anterior centuria.

(*) No hay que olvidar los estudios realizados por Jesús Millán, Juan Bta. Vilar y J. A. Ramos Vidal, pioneros en la empresa de intentar la aproximación al conocimiento histórico de la comarca. 
La obra parte de un presupuesto básico como es el análisis de la estructura social y la distribución de la riqueza dentro de una ciudad realenga, Orihuela, en los albores del siglo XVIII. Este análisis, desarrollado a lo largo del primer capitulo a partir del Padrón de 1717, presenta a Orihuela como el único núcleo urbano importante del Bajo Segura, foco de atracción y asentamiento de numerosa población en virtud de su condición de sede política, religiosa y cultural.

La vida económica está presidida por un marcado carácter rural debido a que la mayor parte de las rentas y actividades de los habitantes están directamente relacionadas con la explotación de la tierra. La cúpula de la pirámide social está claramente dominada por una oligarquia urbana compuesta por nobles, caballeros y eclesiásticos residentes, en su práctica totalidad, dentro del recinto ciudadano. Este estamento de privilegiados acaparó, desde el siglo XVII, todos los cargos municipales merced al sistema insaculatorio y, tras la Guerra de Sucesión y la instauración de la Nueva Planta borbónica, siguió disfrutando de sus prerrogativas sin cambios ostensibles. La principal fuente de ingresos provenía del disfrute de la propiedad agraria y de las rentas generadas por su explotación; propiedades que no se limitaban al perímetro de la ciudad sino que debían ampliarse a los términos realengos circundantes. David Bernabé constata que entre los mayores detentadores de tierras se encontraban no pocas mujeres 10 que induce a pensar, habida cuenta de la endogamia existente entre las grandes familias propietarias de la zona, en la paulatina acumulación y formación de notables patrimonios.

No obstante, dentro del estamento privilegiado, se detectan casos de empobrecimiento progresivo en elementos pertenecientes al grupo de hidalgos locales que no podían soportar los excesivos gastos que el mantenimiento de su status comportaba. Por otro lado, también es de resaltar que, en términos generales, las rentas agrícolas de los privilegiados se veían mermadas, en multitud de ocasiones, debido a las pensiones generadas por censales cargados en fechas pasadas y que debían satisfacer anualmente, asi como por las hipotecas a las que estaban sometidas sus propiedades.

El sector de comerciantes juega un papel poco significativo dentro de la actividad económica ciudadana debido al limitado número de comerciantes mayoristas. La élite de estos comerciantes la constituian ciudadanos franceses asentados en Orihuela el siglo anterior, y se ocupaban en la venta al por menor de ropas importadas de Francia, la comercialización de la seda y en la exportación a ámbitos próximos de ciertos productos agrícolas adquiridos a los grandes cosecheros. Extraña la no vinculación de estos elementos a la propiedad agraria para integrarse en el grupo de privilegiados rústicos, como sucedia por ejemplo en la huerta alicantina, no pareciendo muy aceptable la hipótesis de que cultivaran tierras mediante contratos de arrendamiento. 
Los artesanos, de los cuales es difícil precisar su número, no se muestran como un grupo social potente debido, fundamentalmente, al carácter restringido del mercado con el que contaban. El sector que mayor nivel de contribución reseña el Padrón es el alimenticio-panaderos, confiteros, cereros...-, aunque el que mayor número de individuos agrupa es el textil pese a que las bases imponibles de sus miembros son más limitadas. El resto de los componentes del sector artesano tienen una menor incidencia económica en la vida ciudadana, siendo frecuente que recurrieran al empleo como jornaleros para obtener el mínimo de ingresos necesario para vivir.

La problemática del campesinado queda esbozada en este primer apartado, indicando el autor un desarrollo más profundo en el resto de los capítulos, labor que realiza con gran acierto y espíritu crítico una vez puestas de manifiesto las condiciones en las que se desenvuelve la agricultura en la primera mitad del siglo XVIII. En este período, brillantemente descrito en el capítulo $2 .^{\circ}$, se pone de manifiesto el avance de la productividad agrícola gracias a los rompimientos o roturaciones de tierras, que permitieron la puesta en cultivo de nuevas superficies. La no transformación de las técnicas de cultivo motivó un descenso de los rendimientos a largo plazo así como serias dificultades para el campesinado, a quien la roturación de gran número de tierras comunales había privado de una serie de ingresos complementarios. Entre ellos, el derivado de la utilización, por parte de una reducida cabaña lanar, de las dehesas concejiles convertidas, por mor de las roturaciones, en tierras aptas para el cultivo. Fenómeno similar es observable en la Bailía de Alicante hacia fines del XVIII, debiendo el Ayuntamiento poner coto a los abusos de los particulares y denengando de forma sistemática gran número de solicitudes para llevar a cabo roturaciones de tierra.

La ausencia de padrones locales, que permitirian evaluar la superficie cultivada asi como la distribución de los cultivos, supone un obstáculo para el autor de Tierra y sociedad en el Bajo Segura puesto que restan un cúmulo de datos sin desvelar. No obstante, utilizando información diezmal, nos ofrece noticias sobre las huertas de Catral y Redován. Esta última, sujeta al dominio directo del Colegio de Predicadores, presenta un predominio del cereal, olivares y moreras. Catral presenta las mismas características de agricultura de subsistencia poco diversificada y basada, esencialmente, en el cultivo del cereal y el cáñamo.

En la primera mitad del siglo XVIII se produjo una expansión de las producciones no cerealísticas-lino, cebada, barrilla, morera-que revelaría una cierta atracción de los mercados vecinos, aunque resulta extraño el hecho de que no llegara a existir un artesanado local capaz de absorber y elaborar las materias primas. 
Pero el núcleo del trabajo se ocupa de desvelar el poderío económico de la iglesia y la situación del campesiado en las zonas de dominio realengo y señorial. En el Bajo Segura, el estamento eclesiástico se configura como el gran acaparador del excedente producido en la comarca e incluso fuera de los límites de la misma. Por lo que respecta a cantidades en metálico, el clero ingresaba en sus arcas dinero por diferentes conceptos. Uno de ellos era el relativo a las pensiones de censales pues, desde siempre, el desempeñar funciones de prestamista había supuesto uno de los capitulos fundamentales dentro de la economía clerical y le permitia obtener una serie de ingresos fijos anuales. Otras percepciones en metálico se refieren a los cánones de las tierras arrendadas o cedidas en enfiteusis, asi como a las rentas derivadas de la propiedad rústica o urbana.

En especie también recibía el clero imortantes aportaciones provenientes del diezmo de la producción agrícola del obispado, de las participaciones de frutos de sus enfiteutas y de lo estipulado en la explotación directa de sus tierras.

De este modo, la Iglesia actuaba como un gran almacenista de productos agrícolas comercializables por lo que, en ningún momento se veía afectada por malas cosechas o coyunturas económicas depresivas. Desde el XVIII el clero desarrollará una gran labor inversora en la compra de tierras y participará activamente en los nuevos establecimientos y roturaciones, convirtiéndose en el principal beneficiario de la expansión agrícola. A ello hay que añadir las respetables superficies de tierra que recibia en concepto de donaciones o herencias de fieles.

La Iglesia derivó, con el devenir del 'siglo, hacia posiciones claramente rentistas, impidiendo que la economia agraria pudiera avanzar hacia formas capitalistas debido a la dilapidación de sus fortunas en gastos suntuarios, alimento de pobres, caridad y beneficencia.

La participación del estamento eclesiástico en el total de la superficie cultivada del realengo oriolano era muy notoria, puesto que disfrutaba de la mayor parte del terrazgo en compañía de la oligarquía local y la nobleza foránea. Esta élite terrateniente acumulaba más de la mitad de la superficie útil realenga pese a que, numéricamente, suponia tan sólo el $13 \%$ del total de propietarios - que componia la fuerza más dinámica del sector-y los pequeños propietarios-casi el $50 \%$-que disfrutaban de parcelas con superficies exiguas, aspecto éste mucho más acusado en el regadio que en el secano.

La forma juridica de tenencia de la tierra imperante en el realengo era el arrendamiento. Es al tratar este aspecto donde aparecen los únicos puntos oscuros de todo el estudio. Cuando el autor se refiere a la escasa participación de la oligarquía local como arrendatarios, reseñándola como aspecto destacable, y la contrapone a los innumerables casos de propieda- 
des cedidas en arriendo por eclesiásticos y caballeros se intuye una confusión entre los términos arrendador y arrendatario; confusión que, por otro lado, queda despejada al encontrar en el texto, más adelante, una clara referencia a la frecuente figura del rentista intervencionista-que lo serian la mayor parte de los oligarcas locales-que impone duros capítulos a sus arrendatarios en el momento de signar el contrato de arriendo.

Las condiciones de los arrendamientos son exhaustivamente descritas por David Bernabé gracias al muestreo realizado sobre protocolos notariales y al hallazgo de un documento que pormenoriza cuáles son las características del cultivo de las tierras «a uso y costumbre de buen labrador", permanente citado en todos los arriendos. En este capítulo se encuentra una gran aportación al conocimiento de la situación en que se hallaba la gran masa campesina, la cual en términos reales era crítica y en el límite de la subsistencia por no poder acceder ni siquiera a la labranza de pequeñas superficies agrarias. Los motivos de esta situación los ha captado perfectamente el autor: por un lado, la creciente privatización de tierras comunales y, por otro, la carencia de un capital mínimo que permitiera iniciar la explotación de las propiedades que, en grandes y medianos lotes, arrendaban los rentistas. El carácter marcadamente intervencionista de éstos últimos respecto a los cùltivos a desarrollar por sus arrendatarios supuso una transformación importante en el paisaje agrario.

Pese a las condiciones favorables para el desarrollo de un capitalismo agrario en el realengo, los obstáculos fueron múltiples y, sobre todo, no llegó a consolidarse la alianza objetiva entre clase rentista y arrendatarios. Si acaso se echa en falta en este capítulo una referencia a la incidencia de la enfiteusis, sobre todo porque seía un interesante punto de referencia y comparación respecto a la existente en el vecino realengo alicantino en el que la corona tenía establecidos una serie de tierras, casas, hornos y molinos a vecinos de la ciudad y lugares circundantes, de los que anualmente percibía un canon en metálico.

Tierra y sociedad en el Bajo Segura se cierra con dos interesantes y clarificadores capítulos relativos al importante papel jugado por el señorio alfonsino en la zona en una etapa en que el crecimiento demográfico y económico abria amplias expectativas en lo que a puesta en explotación de grandes superficies agrarias se refiere.

En un contexto en el que la estructura social muestra una amplia capa de campesinos sin tierra y una élite rentista que únicamente transige cediendo sus propiedades en arriendos nada ventajosos, la posibilidad de utilizar el contrato enfitéutico ofrecía mayores atractivos, sobre todo a los campesinos que, de este modo, disponian de un cierto margen para obtener rendimientos agrícolas aceptables sin necesidad de hacer un desembolso previo de capital. 
Por otro lado, los propietarios, acogiéndose al Privilegio 78 de la rúbrica foral "De iurisdictione omnium iudicum" concedido en 1239 por Alfonso II, accedian, tras disfrutar de la propiedad de la tierra y cederla en enfiteusis al menos a 15 pobladores, al disfrute de la jurisdicción señorial. La proliferación de estos señorios en el Bajo Segura vendría dada por ese deseo de ampliar la superficie explotada, por la necesidad de garantizar la puesta en cultivo sin gastos de acondicionamiento y, por qué no, por el interés en disfrutar ciertos derechos económicos y juridicos complementarios. David Bernabé documenta el establecimiento del señorío de Molins de Rocamora, y la repoblación, por el Colegio de Predicadores del de Redován y Hondones.

Respecto al primero, creado en 1697 tras establecer D. Alonso Rocamora y Molins en la Partida de Correntía-Huerta de Orihuelalos 15 pobladores que el privilegio Alfonsino determinaba, los capítulos de su Carta Poblacional presentan un relativo recrudecimiento de la presión señorial. El Señorío de Redován, adquirido por los Dominicos del Colegio de Predicadores en 1615 , presenta rasgos más interesantes. La característica del Colegio a lo largo de su existencia había sido la vinculación a cualquier actividad que constituyera un soporte económico, estando pues siempre interesado en ampliar su patrimonio aprovechando la coyuntura de cada momento para invertir en bienes rústicos o urbanos. Desde esta óptica, la actuación de los Dominicos a lo largo del siglo XVII consistió en adquirir tierras incultas y abandonadas por la regresión demográfica pero de las que, con el tiempo y una buena organizacion, esperaban extraer rentabilidad. Esta actitud fue motivo de múltiples choques con el Cabildo Catedralicio Oriolano que veía menguar sus ingresos, pues las tierras adquiridas por el Colegio al dejar de ser consideradas como seglares, cesaban en el pago de los diezmos y el subsidio.

Dentro de este contexto inversionista encaja la compra del señorio de Redován y las posteriores actuaciones del Colegio de Predicadores. Este, en principio, estableció colonos en sus tierras mediante contratos enfitéuticos pero a medida que avanzaba el siglo XVIII, y a la vista del estancamiento de las rentas en metálico, comenzó a asimilar y comprar el dominio útil de muchas parcelas, reduciendo de este modo las posesiones de sus enfiteutas. Acto seguido inició la explotación directa de las mismas mediante arriendos a corto plazo incrementando además sus ingresos gracias al arriendo de las regalías del señorio.

En síntesis, David Bernabé clarifica la actuación del Colegio de esta manera:

-Donde existían superficies incultas abundantes atrajo pobladores para que las pusieran en cultivo, obteniendo de este modo los beneficios de la partición de frutos. 
-Si las tierra escaseaban se imponian condiciones onerosas a los nuevos enfiteutas.

-En último caso, el Colegio consolidaba el dominio útil y el directo cediendo estas tierras en arriendo.

La exposición queda cerrada con la presentación de una muy sugerente hipótesis: el Colegio de Predicadores devino, a lo largo del XVIII, en un empresario agrícola puesto que comercializaba sus propias producciones. Si a esto se la suma la utilización constatada de trabajadores asalariados nos encontraríamos con los rasgos evidentes de un incipiente capitalismo, que vendría a confirmar ese claro dominio económico de los sectores eclesiales en la comarca estudiada.

Tierra y sociedad en el Bajo Segura (1700-1750) es, en suma, un libro que destila abundante espíritu crítico a lo largo de sus páginas y que, mediante una exposición escueta y clara pero ampliamente documentada, nos aproxima al conocimiento de los aspectos fundamentales de la historia agraria de esta comarca que tan señero papel ha desempeñado desde. el punto de vista económico, cultural y religioso. 